of China, the more I came to understand and hospital with several wards for one or two sympathize with that point of view.

To me the idea of studying the location where needles should be placed is misconceived. If you want to make acupuncture work, attention will have to be directed not to the acupuncturist, but to screening patients and popping needles at random into those susceptible to hypnosis and who have a strong motive for it to be successful. It must be remembered that the Chinese people are, with good reason, intensely grateful to Chairman Mao, and that he has throughout championed traditional medicine, the only medicine available at the time for the masses who supported him during his years of turmoil. Understandably, motivation for acupuncture to be successful is great.

It would be an easy matter to test whether accurate siting of the needles or the mental approach of the patient is the more important factor in achieving success. There would be no difficulty in obtaining the necessary expenses for a leading acupuncturist to travel to Britain and exhibit his skills at any emergency operation, or at any routine operating list for general surgery in the country. If the patients are chosen at random, I confidently predict a success rate of nil. I believe that faced with cholecystectomy, acupuncture needles bear a similar relationship to ether as does a bottle of coloured medicine to penicillin in the treatment of septicaemia.

I would stress that I write not to denigrate acupuncture-far from it-but to express my belief that, if someone can explain hypnotism to me, I am confident that the secret of acupuncture will be revealed at the same time. I concur entirely with the view that "acupuncture is an effective use of hypnosis. This in no way dismisses the value of acupuncture, but it does place it in a class of phenomena with which we are partly familiar." ${ }^{\prime}$ - I am, etc.,

\section{Robert Macintosh}

Nuffield Department of Anaesthetics,

Radcliffe Infirmary,
Oxford 1 Esdaile, J., Mesmerism in India and its ApLongmans, 1846.

Mason, A. A., Anaesthesia, 1955, 10, 295.

Brown, P. E, Lancet, 1972, $1,1328$.

Sutherford, K., China Now, 1972, 24, 7.

6 Wall, P., New Scientist, 1972, 55, 129. 29.

\section{Surgical Wound Infections}

SIR,-The design of surgical wards probably has a profound influence on the rate of wound infection, but this has not been the subject of a controlled clinical trial. Sequential review of the infection rate in Aberdeen after moving from a pavilion-type ward to one with single rooms and plenum ventilation has shown a reduction of wound infections, even of endogenous type by intestinal organisms. ${ }^{12}$

In the course of two trials on the prevention of surgical wound infection by cephaloridine $^{34}$ we have found that the infection rate in comparable wounds is less in the War Memorial Hospital, Whitby, than in Scarborough Hospital. The latter is a district general hospital with large, open, "Nightingale" wands, each of 30 beds, in which all types of surgical patient are nursed. The Whitby hospital is a cottage patients and eight-bedded male and female wards for both medical and surgical patients.

In wounds with no potential for endogenous infection ("clean") there were no infections among 117 Whitby cases compared with $20(5.1 \%)$ among 388 Scarborough cases $\left(x^{2}=6.25, P<0.02\right)$. In contaminated cases (involving the excision of infected lesions) the infection rate was lower in Whitby (11/91, $12.1 \%)$ than in Scarborough (53/349, $15.9 \%$ ), but the difference was less significant $\left(x^{2}=0.55\right)$.

It is unlikely that the better results in the Whitby hospital are due to the design of the operating theatres (which is similar in the two hospitals) or the nature of the operations (complicated operations were excluded from the comparison because they were done in Scarborough). The contrast is more likely to be in the size of the wards, which are much bigger and busier in Scarborough.

Probably the ideal milieu from the point of view of avoidance of exogenous wound infection is the patient's own home. We have recently operated (for hernias, varicose veins, etc.) on 111 patients who stayed in Scarborough Hospital for only 24 hours altogether. There were no wound infections in this series.-I am, etc.,

\section{Scarborough Hospital,
Scarborough, Yorks.}

Smylie, H. G., Davidson, A. I. G., Macdonald, A., and Smith, G., British Medical fournal, 1971, $1,67$.

and Smith I. G., Smylie, H. G., Macdonald, A 1,72 .

3 Evans, C. M., and Pollock, A. V., British fournal 4 Evans, Surgery, $1973,60,434$. A. V., British fournal
of Pollock, A. V., and Rosenberg. I. L. $\because$ o be published.

\section{Late Advertising of Hospital Posts}

SIR,-Professor R. S. Illingworth (4 August, p. 289) asks for more consideration for junior doctors in the timing of advertisements for hospital posts. The contents of many such advertisements leaves much to be desired. Relatively few give any indication of the nature of the job (apart from medical or surgical, etc.), the experience required, or the experience to be gained while doing the job. Postgraduate facilities are rarely mentioned. It may be argued that a telephone call to the hospital secretary is all that is required to obtain further details. The last time I rang a hospital secretary for information about a post, in particular the number of junior staff on the firm, I was given quite incorrect information. Professor Illinfworth also points out that sometimes applications have to be sent in almost within hours of the advertisement appearing. Some hospital administrators do not seem to think that such haste should apply to them. One teaching hospital took three months to write and tell me that I had not been offered a post.

If hospitals wish to attract high-quality junior staff, then the standand of advertising must improve. I feel that hospital conthis. They should vet all advertisements for sultants have an important part to play in their junior staff and insist that administrators should place comprehensive advertisements. After all, it is the consultants and their junior staff, not the administrators, who suffer if only unsuitable candidates apply. Some hospitals place exemplary advertisements-why can't the rest?

Another problem is whether a post is resident or not. There seems to be no consensus of what constitutes a resident post. I have just been offered a locum registrar post which is non-resident-yet I am compelled (by the administrators, not the consultants) to live in when on call. This is every other night and alternate weekends. If one is to be resident for the maximum recommended time, then surely the post should be resident. Alternatively, if one is forced to buy a house, with the inevitable heavy mortgage, then one should be allowed to go and live in it. I feel that distinctions between resident and non-resident posts are often made for administrative convenience as opposed to medical requirements.-I am, etc.

Copthorne, Sussex

D. H. WRIGHT

SIR,-Professor R. S. Illingworth (4 August, p. 289) complains that (1) many junior hospital posts are "out of step" and (2) many senior house officer and preregistration posts are advertised very late and within a few days of the start of the appointment.

With regard to the first complaint he will be pleased to know that real efforts are being made to synchronize the junior hospital appointments throughout the U.K., with growing success. With regard to the second there is a reason why some preregistration appointments are advertised late and it is difficult to see how it can be avoided. Preregistration appointments are taken up by the newly qualified doctor and the posts are allocated by computer or otherwise before the final examination in June. Inevitably a few students fail the exam and are therefore unable to take up their appointments in August, so that they then have to be advertised in July. This does not apply of course to S.H.O. appointments, but here I am sure Professor Illingworth knows that not a few S.H.O.s leave their posts before termination through having obtained a registrar post or for other reasons, so that a late advertisement is not necessarily evidence of "administrative inefficiency and incompetence" or "thoughtlessness for the doctors."-I am, etc.,

ARNOLD S. ALDIS,

Director and Dean of Postgraduate Studies Welsh National School of Medicine,

\section{Promotion of Research on Deafness}

SIR,-According to the Chronically Sick and Disabled Persons Act, under section 24, the Department of Health and Social Security was charged in 1970 with the responsibility of collating and presenting to the Medical Research Council information on the case for an institute of hearing research with the function of co-ordinating and promoting research on hearing and assistance to the deaf and thard-of-hearing. This report, compiled by Dr. Annette Rawson using information 